\title{
Publisher Correction: Database-independent molecular formula annotation using Gibbs sampling through ZODIAC
}

Marcus Ludwig (D), Louis-Félix Nothias (D), Kai Dührkop (D), Irina Koester D, Markus Fleischauer, Martin A. Hoffmann (D), Daniel Petras (D), Fernando Vargas, Mustafa Morsy, Lihini Aluwihare, Pieter C. Dorrestein and Sebastian Böcker (iD)

Correction to: Nature Machine Intelligence https://doi.org/10.1038/s42256-020-00234-6, published online 13 October 2020.

In the version of this Article originally published, in the Methods section, some of the mathematics formatting was incorrect. In the subsection 'Graph-theoretical formulation,' ' $\left(\begin{array}{l}V \\ 2\end{array}\right)$ ' was twice given incorrectly as '( $\left.0.0 p t V 2\right)$ '; in Lemma 1 , ' $G=(V, E)$ ' was incorrectly given as ' $g=(v, e)$ ', and ' $G$ ' as ' $g$ '; in Lemma 2 , ' $O(|V(c)|+\operatorname{deg}(u)+\operatorname{deg}(v))^{\prime}$ was incorrectly given as ' $O(+\operatorname{deg}(u)+\operatorname{deg}(v))$ '. $\operatorname{All} v e r s i o n s$ of the Article have been corrected.

Published online: 21 October 2020

https://doi.org/10.1038/s42256-020-00259-x

(c) The Author(s), under exclusive licence to Springer Nature Limited 2020 